Ćirić Vojislav리 Kocić Hristina², Kocić Radivoj ${ }^{1}$

\title{
OKSIDATIVNI STRES KAO RANI MARKER SUPKLINIČKE HIPERTIREOZE - KORELACIJA SA HORMONSKIM POKAZATELJIMA
}

\begin{abstract}
Apstrakt: Supklinička hipertiroza se definiše kao stanje sa najčešće normalnim nivoom tiroidnih hormona, smanjenim nivoom TSH i retko izraženim znacima tirotoksikoze. Nedostatak specifičnih ranih znakova hipertireoze, zajedno sa normalnim vrednostima tiroidnih hormona, otežava ranu dijagnostiku supkliničke hipertireoze. Pacijenti sa manifestnom hipertireozom pokazivali su izraženiji disbalans u parametrima oksidativnog stresa nego pacijenti sa supkliničkom hipertireozom u odnosu na kontrolnu grupu, posebno nivo MDA u eritrocitima. Nivo lipidne peroksidacije (MDA) u plazmi bio je u rangu normalnih vrednosti kod pacijenata sa supkliničkom hipertireozom, dok kod pacijenata sa manifestnom hipertireozom u plazmi su detektovane niže vrednosti MDA. Smanjeni nivo lipidne peroksidacije u plazmi praćen je smanjenim nivoom lipoproteidna, triglicerida i holesterola, gde masne kiseline triglicerida i lipoproteina predstavljaju značajne supstrate lipidne peroksidacije u plazmi. Aktivnost ksantin-oksidaze bila je značajno povećana kod pacijenata sa manifestnom formom hipertireoze, ali bez statistički značajne razlike kod pacijenata sa supkliničkim formama bolesti. Na osnovu svega može se zaključiti da promene na nivou eritrocita mogu biti jedan od značajnih pokazatelja poremećene homeostaze slobodnih radikala i lipida u ćeliji, pa se mogu razmatrati kao mogući marker za obolevanje od manifestne hipertireoze u supkliničkim oblicima. Dobijeni rezultati mogu da ukažu i na to da rana antioksidativna terapija može da predupredi razvoj manifestne hipertireoze.
\end{abstract}

Ključne reči: supklinička hipertireoza, slobodni radikali, lipidna peroksidacija, ksantin oksidaza

Klinika za endokrinologiju Medicinski fakultet Univerziteta u Nišu.

Medicinski fakultet Univerzitet u Mariboru, Maribor Slovenija. 


\section{Uvod}

U dijagnostikovanju supkliničke hipertireoze bilo je dosta pokušaja u iznalaženju ranog markera $(1,2)$. Supklinička hipertireoza se definiše kao stanje sa najčešće normalnim nivoom tiroidnih hormona, smanjenim nivoom TSH i retko izraženim znacima tirotoksikoze (3-5). Problem nastaje u podatku koji je dala American Thyroid Association, da od ukupnog broja registrovanih pacijenata sa supkliničkom hipertireozom oko 5\% godišnje pređe u manifestni klinički oblik (6). Ukoliko se imaju u vidu posledice koje u sistemskom smislu tiroidna hiperfunkcija ostavlja za sobom, kao što su kardiovaskularne bolesti, rana detekcija je prioritet (7-9). Rutinski skrining nivoa TSH bio bi dovoljan, a svaka vrednost ispod $0.1 \mathrm{mU} / \mathrm{L}$ vrlo indikativna $(3,6)$.

Povećana produkcija slobodnih radikala pokazana je na nizu animalnih modela i kliničkih studija u stanjima hipertiroidizma (10-13). Tiroidni hormoni snažno aktiviraju bazalni metabolizam, koji znači potrošnju kiseonika, tj. oksidativnu fosforilizaciju na nivou mitohondrija ćelija. Tada dolazi do oslobađanja superoksidnog anjona, prvog radikala od koga može nastati vodonik-peroksid. Kako slobodni radikali predstavljaju važne komponente odgovorne za proliferaciju fibroblasta, retrobulbarno, to je jedan od mehanizama u nastanku oftalmopatije (14).

Studija je imala za cilj da se ustanovi nivo produkata lipidne peroksidacije u osoba sa supkliničkom i manifestnom hipertireozom, kako bi se ukazalo na to da li je oksidativni stres u korelaciji sa progresijom bolesti.

\section{Pacijenti i metode}

\section{Pacijenti}

Supklinička hipertireoza je dijagnostikovana u skladu sa preporukama Subclinical hyperthyroidism was diagnosed according to the guidelines for diagnosis and management of subclinical thyroid diseases $(4,5)$. Pacijenti su dijagnostikovani na Klinici za endokrinologiju i bolesti metabolizma Kliničkog centra Medicinskog fakulteta u Nišu.

Ulazni kriterijumi: Ova studija je uključila pacijente sa dijagnostikovanom hipertireozom $(\mathrm{N}=18$; godine starosti 31 do 64 , srednja starosna dob $42.7 \pm 6.5$ godina; 11 žena i 7 muškaraca) i pacijente sa supkliničkom hipertireozom (N=15; 29 do 66 godina starosti; srednja starosna dob $44.9 \pm 8.5$ godina; 12 žena i 3 muškarca). Pacijenti sa supkliničkom hipertireozom su bili podeljeni u dve podgrupe (I i II), u odnosu na nivo TSH (vrlo nizak, ispod $0.1 \mathrm{mU} / \mathrm{L}$ grupa I) i niske vrednosti TSH $(0.1-0.45 \mathrm{mIU} / \mathrm{L}$ grupa II). Kontrolne vrednosti su dobijane od osoba koje su bile dobrovoljni davaoci krvi (N=36, 20 žena i 16 miškaraca). Manifestna hipertireoza je bila dijagnostikovana na osnovu postojanja nodusa ili difuzne strume, tj. nalaza dobijenog na ultrazvuku, 
pregleda radioaktivnim jodom-123 i merenja nivoa tiroidnih hormona. Pacijenti sa manifestnom hipertireozom su imali znake hipertiroidizma, kao što je tahikardija, aritmija, mišićni zamor, depresija, anksioznost, tremor, gastrointestinalne smetnje, dok su pacijenti sa supkliničkim formama imali daleko slabije izražene pomenute simptome, kao što je anksioznost, blaža disritmija, mišićni zamor. ispitivan je profil lipoproteina i triglicerida (tabela 1).

Kriterijumi za isključivanje: Studija nije obuhvatala pacijente koji su prethodno bili na terapiji zbog poremećaja funkcije štitne žlezde, koji su imali operaciju na štitnoj žlezdi ili su imali još neko udruženo oboljenje, kao što je diabetes mellitus, hipertenzija, istorija autoimunskih bolesti, kardiovaskularnih bolesti, cerebrovaskularnih bolesti, bubrežnih bolesti ili bilo kojih drugih stanja koja bi mogla imati uticaja na inicijaciju oksidativnog stresa.

\section{Metode}

Uzorci krvi: Venska krv je uzimana u vakutanerima ujutru nakon 12-časovnog odmora i gladovanja. Nakon centrifugiranja heparinizovana plazma je odvajana a talog eritrocita tri puta ispiran u fiziološkom rastvoru. Eritrociti su resupendovani i hemolizirani, pa je hemolizat korišćen za analize. Sve analize oksidativnog stresa su rađene kao što je ranije navedeno, a to su nivo lipidnih peroksida u eritrocitima i plazmi, kao i nivo MDA i ksantin-oksidaze u plazmi. Rezultati za lipidnu peroksidaciju izražavani su kao nmol MDA/ml RBC i MDA u plazmi kao $\mu \mathrm{mol} / \mathrm{L}(2018,19)$. Ksantin-oksidazna aktivnost u plazmi je merena po metodi Kizakija i Sakurade, bazirana na oslobađanju mokraćne kiseline iz ksantina kao supstrata. Aktivnost je izražavana kao IJ/L. (20).

Rezultati su prikazani kao srednja vrednost $\pm \mathrm{SD}$. Analiza varijanse je korišćena za komparaciju između grupa. Statistička značajnost je označavana za $\mathrm{p}<0.05$.

\section{REZULTATI}

Pacijenti sa manifestnom hipertireozom su pokazivali izraženiji disbalans $\mathrm{u}$ parametrima oksidativnog stresa nego pacijenti sa supkliničkom hipertireozom $u$ odnosu na kontrolnu grupu (grafikon 1). To se odnosi na nivo MDA u eritrocitima. Nivo lipidne peroksidacije (MDA) u plazmi bio je blizu normalnih vrednosti kod pacijenata sa subkliničkom hipertireozom, dok su kod pacijenata sa manifestnom hipertireozom u plazmi detektovane niže vrednosti MDA. Smanjeni nivo lipidne peroksidacije u plazmi praćen je smanjenim nivoom lipida, tj. triglicerida i holesterola, gde masne kiseline triglicerida i lipoproteina predstavljaju značajne supstrate lipidne peroksidacije u plazmi. Aktivnost ksantin-oksidaze je bila značajno povećana kod 
pacijenata sa manifestnom formom hipertireoze, ali bez statistički značajne razlike kod pacijenata sa supkliničkim formama bolesti (grafikon 2). Nalazi holesterola i triglicerida prikazani su na grafikonu br. 2 .

\section{DISKUSIJA}

Povećan nivo tiroidnih hormona aktivira niz signalnih mehanizama u ćelijama, koji aktiviraju membranski transport, modulaciju enzimske aktivnosti intermedijarnog metabolizma, aktivaciju elektron-mitohondrijalnog transporta uz povećanu produkciju energije, aktivaciju transkripcionih faktora, kao što je nuklearni faktor NF- $\kappa \mathrm{B}$ (21). Oslobođeni slobodni radikali na nivou intraćelijskog miljea oštećuju ćelije. Zbog toga su eritrociti kao ćelije veoma pogodni za proučavanje intracelularnih mehanizama oštećenja. Pokazano je da u Gravesovoj bolesti dolazi do poremećaja integriteta fosfolipidnog sloja membrane (22-24). Količina holesterola u membranama ćelija se povećava, a u plazmi opada. Povećava se i količina fosfolipida $(13,23)$. Zbog toga se i očekuje povećani nivo MDA u eritrocitima, gde je prisutna povećana količina supstrata za lipidnu peroksidaciju (24). Zbog toga se povećanje ćelijske lipidne peroksidacije, zajedno sa povećanom osetljivošću membrane na oksidativni stres i smanjenje aktivnosti enzima antioksidativne zaštite, može smatrati ranim markerom supkliničke hipertireoze $(25,26)$. Nalazi antioksidativnih enzima u plazmi su različiti (26-29).

Rezultati koji se odnose na smanjeni nivo lipidne peroksidacije u plazmi se unekoliko razlikuju od podataka u literaturi, gde je dokumentovan porast lipidne peroksidacije $(26,27,29,30)$. U našem preliminarnom istraživanju, koje je prezentovalo prikaz slučaja pacijenta sa imunskom komponentom hipertireoze i dijabetesa, više nego tostruki porast lipidne peroksidacije bio je dokumentovan (16). Moguće da su imunski mehanizmi putem aktivacije NF- $\mathrm{B}$ B odgovorni za povećanu produkciju radikala. Ali aktuelna koncentracija triglicerida i holesterola u plazmi nesumnjivo pokazuje da je aktuelna koncentracija supstrata snižena u plazmi. Pored toga, novootkrivene forme oboljenja još uvek ne pokazuju tako pojačanu kaskadu inflamacije i citokinskog porasta kao što je nivo TNF- $\alpha(30,31)$. Rezultati povećane aktivnosti ksantin-oksidaze dokumentovani su u plazmi pacijenata sa hipertireozom (11). Ovaj enzim je važan kao jedan od najznačajnijih producenata slobodnih radikala u cirkulaciji, gde je prisutan iz endotelnih ćelija i ćelija perifernih tkiva, posebno jetre. Sa druge strane, neki rezultati u literaturi pokazali su da raste i koncentracija antioksidativnih enzima pa povećano stvaranje radikala biva neutralisano (32).

U zaključku se može reći da nedostatak specifičnih ranih znakova hipertireoze, zajedno sa normalnim vrednostima tiroidnih hormona, otežava ranu dijagnostiku supkliničke hipertireoze. Na osnovu dobijenih podataka može se zaključiti da promene na nivou eritrocita mogu biti jedan od značajnih pokazatelja poremećene homeostaze slobodnih radikala i lipida u ćeliji, što osobe sa supkliničkom hipertireozom može 
dovesti u povećan rizik za obolevanje od manifestne hipertireoze. Dobijeni rezultati mogu da ukažu i na to da rana antioksidativna terapija može da predupredi razvoj manifestne hipertireoze.

\section{Reference:}

1. Psaltopoulou T, Ilias I, Toumanidis S, Mantzou E, Marafellia P, Piperingos G, Koutras DA, Alevizaki M. (2007) Endogenous subclinical hyperthyroidism: Metabolic and cardiac parameters. Eur J Intern Med. 18(5): 423-429.

2. Premachandra BN, Radparvar A, Williams IK. (2007) Reciprocal relation of thyroid-stimulating hormone and thyroid-stimulating immunoglobulin in a patient with endogenous subclinical hyperthyroidism. Am J Med Sci. 333(5): 296-299.

3. Toft A. (2001) Subclinical Hyperthyroidism. N Engl J Med 345: 512-516.

4. Wiersinga WM. (1995) Subclinical hypothyroidism and hyperthyroidism. Prevalence and clinical relevance. Neth J Med. 46:197-204.

5. Surks MI, Ortiz E, Daniels GH, Sawin CT, Col NF, Cobin RH, Franklyn JA, Hershman JM, Burman KD, Denke MA, Gorman C, Cooper RS, Weissman NJ. (2004) Subclinical thyroid disease: scientific review and guidelines for diagnosis and management. JAMA 291(2): 228-238.

6. Ladenson PW, Singer PA, Ain KB (2000) American Thyroid Association guidelines for detection of thyroid dysfunction. Arch Intern Med. 160: 1573-1575.

7. Belaya ZE, Melnichenko GA, Rozhinskaya LY, Fadeev VV, Alekseeva TM, Dorofeeva OK, Sasonova NI, Kolesnikova GS. (2007) Subclinical hyperthyroidism of variable etiology and its influence on bone in postmenopausal women.6(1): 62-70.

8. Bell RJ, Rivera-Woll L, Davison SL, Topliss DJ, Donath S, Davis SR. (2007) Well-being, health-related quality of life and cardiovascular disease risk profile in women with subclinical thyroid disease - a community-based study. Clin Endocrinol (Oxf). 66(4): 548-556.

9. Cooper DS. (2007) Approach to the patient with subclinical hyperthyroidism. J Clin Endocrinol Metab. 92(1): 3-9.

10. Ruggiero FM, Landriscina C, Gnoni GV, Quagliariello E. (1984) Alteration of plasma and erythrocyte membrane lipid components in hyperthyroid rats. Horm Metab Res. 16(1): 37-40.

11. Mano T, Shinohara R, Iwase K, Kotake M, Hamada M, Uchimuro K, Hayakawa N, Hayashi R, Nakai A, Ishizuki Y, Nagasaka A. (1997) Changes in free radical scavengers and lipid peroxide in thyroid glands of various thyroid disorders. Horm Metab Res. 29(7): 351-354.

12. Huh K, Kwon TH, Kim JS, Park JM. (1998) Role of the hepatic xanthine oxidase in thyroid dysfunction: effect of thyroid hormones in oxidative stress in rat liver. Arch Pharm Res. 21(3): 236-240.

13. Brzezińska-Slebodzińska E. (2005) Effects of triiodothyronine-induced hyperthyroidism on lipid peroxidation, erythrocyte resistance and iron-binding and iron-oxidizing antioxidant properties of plasma in the rabbit. Vet Res Commun. 29(8): 661-670. 
14. Burch HB, Lahiri S, Bahn RS, Barnes S. (1997) Superoxide radical production stimulates retroocular fibroblast proliferation in Graves' ophthalmopathy. Exp Eye Res. 65(2): 311-316.

15. Pavlovic D, Kocic R, Kocic G, Jevtovic T, Radenkovic S, Mikic D, Stojanovic M, Djordjevic PB.(2000) Effect of four week metformin treatment on plasma and erythrocyte antioxidative defense enzymes in newly diagnosed obese NIDDM patients. Diabetes, Obesity\&Metabol. 2: 251-256.

16. Kocic R, Kocic G, Cvetkovic T, Pavlovic D, Radenkovic S, Mikic D. (1998) Oxidative stress in development of diabetes during hyperthyroidism. J Postgrad Med 74: 381.

17. Kocic R, Pavlovic D, Kocic G, Pesic M. (2007) Susceptibility to oxidative stress, insulin resistance, and insulin secretory response in the development of diabetes from obesity. Vojnosanit Pregl. 64(6): 391-397.

18. Andreeva II, Kotemjakin AA, Kishkun AA. (1988) A modified thiobarbituric acid test for measuring lipid peroxidation products. Lab Delo. 1: 41-43.

19. Asakawa T, Matsushita S. (1980) Thiobarbituric acid test for detecting lipid peroxides. Lipids. 14: 401-406.

20. Kizaki H, Sakurada T. (1977) Simple micro assay methods for enzymes of purine metabolism. J Lab Clin Med. 89: 1135-1144.

21. Konukoglu D, Yelke HK, Hatemi H, Sabuncu T.(2001) Effects of oxidative stress on the erythrocyte $\mathrm{Na}+, \mathrm{K}+$ ATPase activity in female hyperthyroid patients. J Toxicol Environ Health A. 63(4): 289-295.

22. De Riva C, Virgili F, Frigato F. (1996) Increased sodium influx and calcium uptake in erythrocytes in hyperthyroidism: role of abnormal membrane lipid levels. Metabolism. 45(6): 707-711.

23. Heemstra KA, Smit JW, Eustatia-Rutten CF, Heijboer AC, Frölich M, Romijn JA, Corssmit EP. (2006) Glucose tolerance and lipid profile in longterm exogenous subclinical hyperthyroidism and the effects of restoration of euthyroidism, a randomised controlled trial. Clin Endocrinol (Oxf). 65(6): 737-744.

24. Abalovich M, Llesuy S, Gutierrez S, Repetto M. (2003) Peripheral parameters of oxidative stress in Graves' disease: the effects of methimazole and 131 iodine treatments. Clin Endocrinol (Oxf). 59(3): 321-327.

25. Bednarek J, Wysocki H, Sowiński J. (2004) Peripheral parameters of oxidative stress in patients with infiltrative Graves'ophthalmopathy treated with corticosteroids. Immunol Lett. 93(2-3): 227-232.

26. Bednarek J, Wysocki H, Sowiński J. (2005) Oxidative stress peripheral parameters in Graves' disease: the effect of methimazole treatment in patients with and without infiltrative ophthalmopathy. Clin Biochem. 38(1): 13-18.

27. Guerra LN, Moiguer S, Karner M, de Molina MC, Sreider CM, Burdman JA. (2001) Antioxidants in the treatment of Graves disease. IUBMB Life. 51(2): 105-109.

28. Wysocki H, Sowinski J. (2004) Oxidation products and antioxidant markers in plasma of patients with Graves' disease and toxic multinodular goiter: effect of methimazole treatment. Free Radic Res. 38(6): 659-664. 
29. Cetinkaya A, Kurutas EB, Buyukbese MA, Kantarceken B, Bulbuloglu E. (2005) Levels of malondialdehyde and superoxide dismutase in subclinical hyperthyroidism. Med Inflamm 1: 57-59.

30. Komosinska-Vassev K, Olczyk K, Kucharz EJ, Marcisz C, Winsz-Szczotka K, Kotulska A. (2000) Free radical activity and antioxidant defense mechanisms in patients with hyperthyroidism due to Graves' disease during therapy. Clin Chim Acta. 300(1-2): 107117.

31. Senturk T, Kozaci LD, Kok F, Kadikoylu G, Bolaman Z. (2003) Proinflammatory cytokine levels in hyperthyroidism Clin Invest Med. 26(2): 58-63.

32. Mayer L, Romic Z, Skreb F, Bacic-Vrca V, Cepelak I, Zanic-Grubisic T, Kirin M. (2004) Antioxidants in patients with hyperthyroidism. Clin Chem Lab Med. 42: 154-158

Tabela 1. Kliničke karakteristike i nivo tiroidnih hormona u ispitivanim grupama pacijenata

\begin{tabular}{|l|l|l|l|}
\hline ANALIZE & \multicolumn{1}{|c|}{$\begin{array}{c}\text { Manifestna } \\
\text { hipertireoza } \\
\mathbf{( N = 2 8 )}\end{array}$} & $\begin{array}{c}\text { Supklinička } \\
\text { hipertireoza } \\
\text { I (N=9) } \\
\text { TSH }<\mathbf{0 . 1} \text { mIU/L }\end{array}$ & $\begin{array}{c}\text { Supklinička } \\
\text { hipertireoza } \\
\text { II (N=6) } \\
\text { TSH 0.1-0.45 mIU/L }\end{array}$ \\
\hline TSH (m U/L) & $0.09 \pm 0.04$ & $0.09 \pm 0.02$ & $0.12 \pm 0.02$ \\
\hline T4 (nmol/L) & $221.4 \pm 12.3$ & $123.7 \pm 18.8$ & $113.5 \pm 23.6$ \\
\hline T3 (nmol/L) & $4.2 \pm 0.18$ & $2.31 \pm 0.23$ & $1.89 \pm 0.26$ \\
\hline FT4 (pmol/L) & $42.6 \pm 5.18$ & $23.7 \pm 6.12$ & $17.3 \pm 3.16$ \\
\hline $\begin{array}{l}\text { Anti Tg-Ab (\% pozitivnog } \\
\text { nalaza) }\end{array}$ & 71.42 & 66.67 & 40 \\
\hline Difuzna struma (\%) & 64.28 & 44.44 & 20 \\
\hline $\begin{array}{l}\text { Nodularna } \\
\text { struma (\%) }\end{array}$ & 35.72 & 55.56 & 80 \\
\hline Familijarna istorija (\%) & 35.71 & 44.45 & 60 \\
\hline Mišićni zamor (\%) & 64.28 & 44.45 & 80 \\
\hline Depresija ili anksioznost (\%) & 85.71 & 66.67 & 77.78 \\
\hline Tahikardija ili aritmija (\%) & 82.14 & & 60 \\
\hline
\end{tabular}




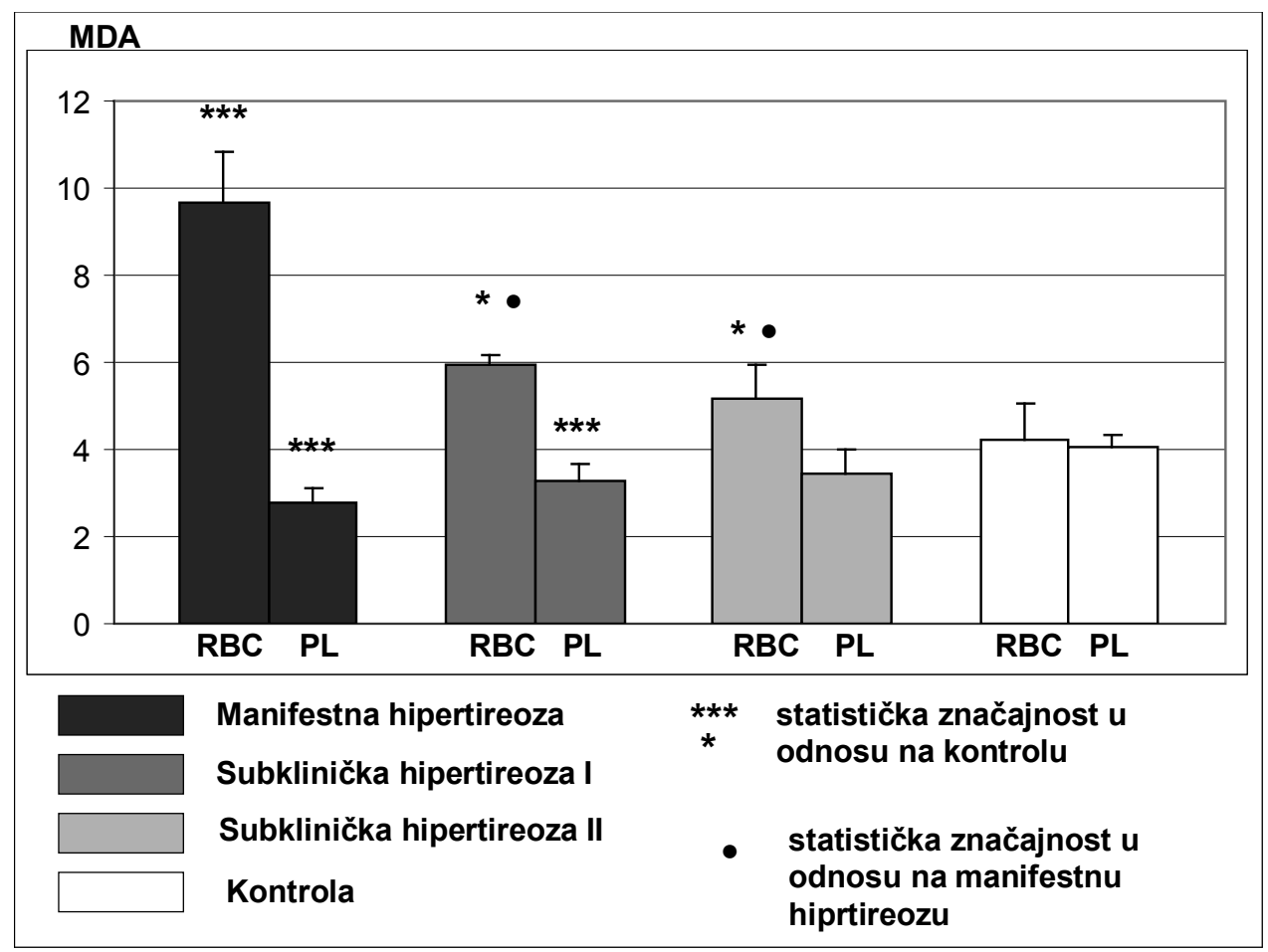

Grafikon 1. Nivo lipidne peroksidacije (MDA) u plazmi i eritrocitima u ispitivanim grupama 


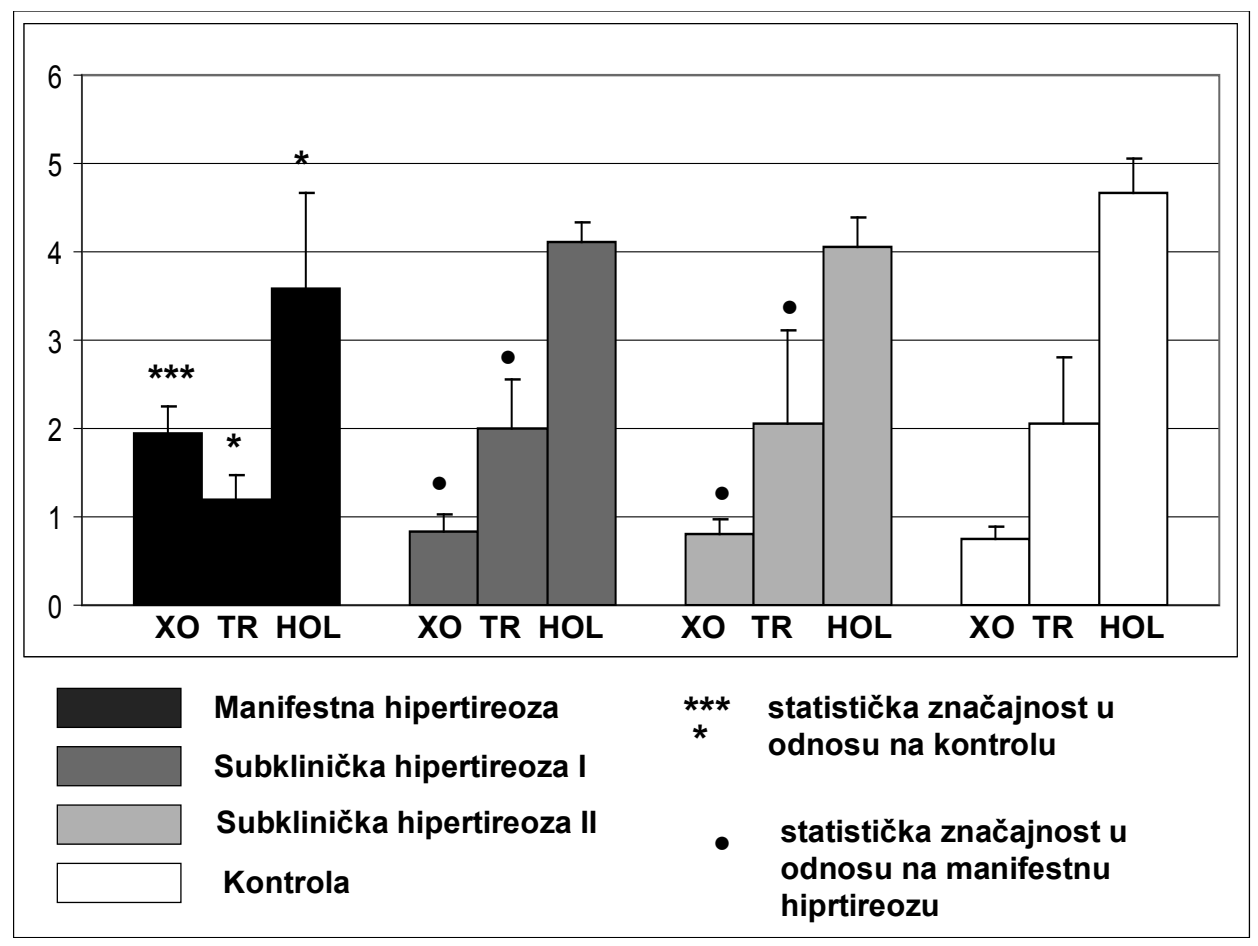

Grafikon 2. Aktivnost ksantin-oksidaze (XO) u triglicerida i holesterola u plazmi u ispitivanim grupama 